\title{
Aerothermal design of Crew Escape System
}

\author{
K. S. Lakshmi ${ }^{1, *}$, M. Ram Prabhu ${ }^{1}$, Rishi Padmanabhan ${ }^{1}$, Ullekh Pandey ${ }^{1}$, \\ M. Manirajan ${ }^{2}$, P. Anoop ${ }^{1}$, T. Sivamurugan ${ }^{3}$, B. Sundar ${ }^{1}$ and M. J. Chacko ${ }^{4}$ \\ ${ }^{1}$ Aeronautics Entity, \\ ${ }^{2}$ Space Transportation System, and \\ ${ }^{3}$ Human Space Technology Group, Vikram Sarabhai Space Centre, ISRO, Thiruvananthapuram 695 022, India \\ ${ }^{4}$ Formerly GD, Aeronautics Entity
}

Crew safety holds highest priority in manned space missions. Crew Escape System (CES) intends to rescue the Crew Module (CM) which accommodates crew members in case of emergency abort situations. Pad Abort Test (PAT) demonstrates the functioning of CES during abort scenarios at the launch pad. CES pulls away CM from the launch pad using specially designed, quick-acting solid Escape Motors. CES-PAT vehicle is engulfed in hot exhaust plumes of these motors during its ascent, exposing the vehicle surfaces to severe thermal environments. Hence estimation of aerothermal heating levels and Thermal Protection System (TPS) design for CES-PAT vehicle structures are mission-critical. Thermal management of avionic packages housed inside $\mathrm{CM}$ is to be ensured for its safe functioning. This article highlights the different aerothermal environments experienced during CESPAT mission, design approaches adopted for estimating heating levels, TPS design and thermal management of avionic systems. Post-flight observations and assessment on aerothermal measurements during CES-PAT mission are also included. Aerothermal measurements confirmed the adequacy of the adopted design approach.

Keywords: Aerothermal design, Crew Module, heat flux, temperature, Thermal Protection System.

\section{Introduction}

INDIAN Space Research Organisation's (ISRO) Human Space Programme (HSP) aims to put a manned Crew Module (CM) in desired orbit and bring them back safely. $\mathrm{CM}$ accommodates the crew and is located in the upper stage of a launch vehicle. It should ensure safe environmental conditions for the crew during all phases of the mission. Being a manned mission, crew safety is of utmost importance demanding man-rated launch vehicle systems and additional safety features in case of launch abort scenarios ${ }^{1}$. Crew Escape System (CES) is a critical system in HSP, intended to separate CM from the launch vehicle to a safer zone in exigency abort situations. CESPad Abort Test (PAT) is aimed to demonstrate the scena-

*For correspondence. (e-mail: lakshmi_kota@vssc.gov.in)

rio of CM separation in the eventuality of launch abort at the launch pad or during atmospheric phase. Figure 1 shows the configuration of CES-PAT vehicle. It consists of quick-acting solid rocket motors, namely Low-altitude Escape Motor (LEM), High-altitude Escape Motor (HEM), Pitch Motor (PM) and Crew Jettisoning Motor (CJM). These motors are fired in a predetermined manner for the safe separation of CM. Grid fins are attached to

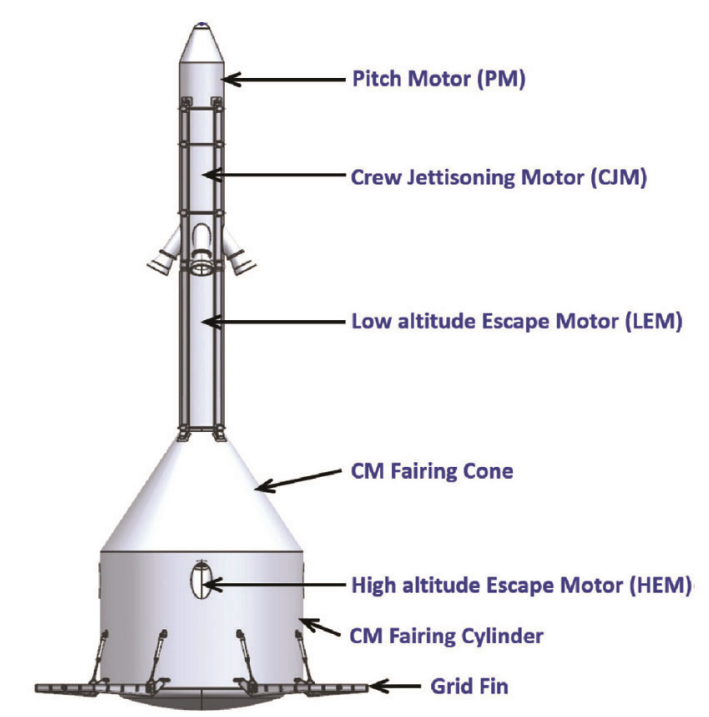

Figure 1. CES-PAT vehicle configuration.

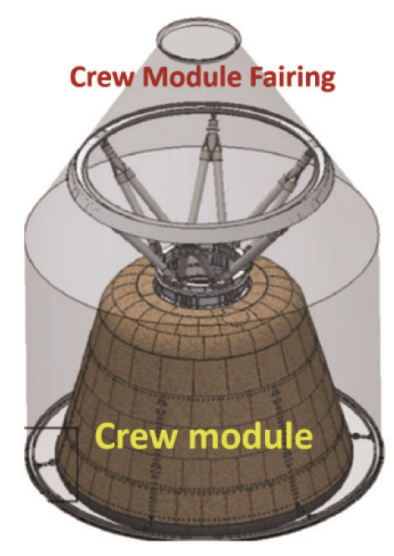

Figure 2. Crew Module inside fairing. 
the base region of CES-PAT to ensure aerodynamic stability of the vehicle. An unmanned CM prototype is housed inside the CM Fairing (CMF) (Figure 2).

Figure 3 shows the CES-PAT mission profile. It involves a total mission duration of $265 \mathrm{sec}$ from lift-off till touchdown. It starts with simultaneous firing of LEM and HEM. PM is fired subsequently to provide desired pitching during lift-off. Later at $\mathrm{T} 0+20 \mathrm{sec}$ with a maximum altitude of $2.7 \mathrm{~km}, \mathrm{CJM}$ is operated and the separated CM is decelerated using parachutes and it splashes into the sea attaining an overall range of $2.9 \mathrm{~km}$ away from the launch pad. CMF shields the CM prototype from these external thermal environments during lift-off and ascent phase. Hence estimation of different aerothermal environments is crucial for Thermal Protection System (TPS) design of vehicle structures. This article covers different aspects of aerothermal heating, TPS design, thermal management of avionic systems and related flight observations in CES-PAT.

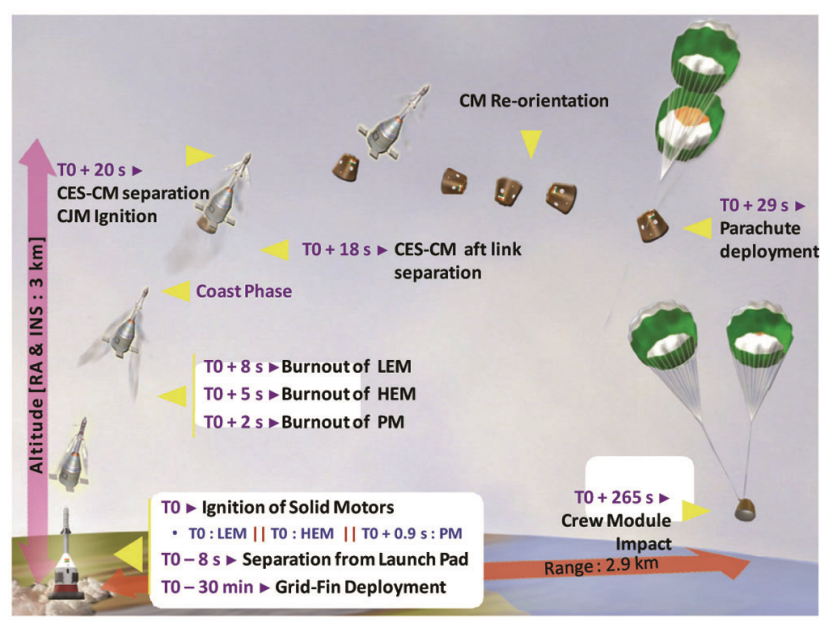

Figure 3. CES-PAT mission profile.

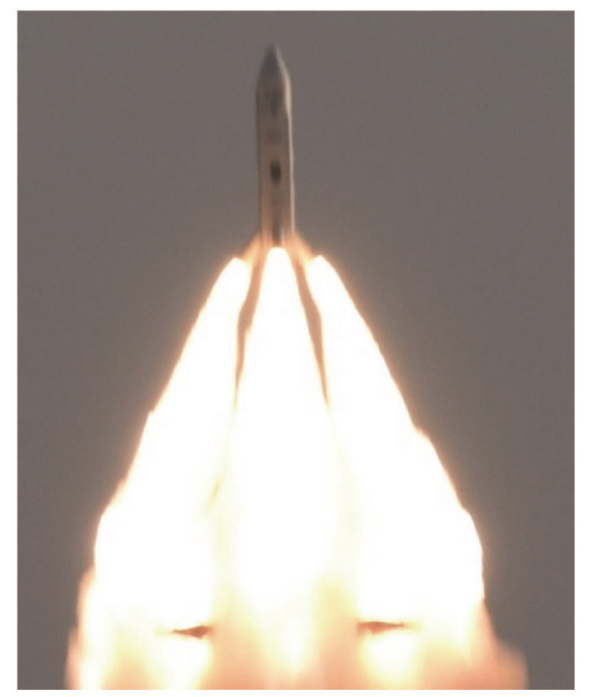

Figure 4. CES-PAT engulfed in hot jet exhausts.

\section{Aerothermal environments}

The external surface of CES-PAT vehicle is subjected to different aerothermal loads which include: aerodynamic heating and exhaust plume heating from various motors. Figure 4 shows the CES-PAT vehicle engulfed in hot-jet exhausts during flight. Aerodynamic heating is experienced during ascent phase of the flight. Exhaust plume heating includes convective heating from gaseous plumes and radiative heating due to solid alumina particles in the exhaust plumes.

\section{Aerodynamic heating}

Aerodynamic heating is estimated based on vehicle geometry and its trajectory. CES-PAT vehicle has a capcone-cylinder geometry with CMF having conical frustum and cylinder region. The exit plane of the nozzle divergents of HEM, CJM and PM is flushed with the vehicle surface to meet aerodynamic requirements. However, the four nozzle divergents of LEM protrude out of the vehicle surface. Figure 5 shows the flight trajectory parameters for CES-PAT. It has a maximum Mach number of 0.78. Engineering method of Van Driest is used for estimating aerodynamic heating levels on the cylinder region $^{2,3}$. Figure 6 shows the estimated heat flux history on the cylinder region of CES-PAT. The estimated maximum total temperature is only $55^{\circ} \mathrm{C}$. Maximum heat flux of $0.07 \mathrm{~W} / \mathrm{cm}^{2}$ is estimated for the cylinder region. Unlike typical launch vehicles, the aerodynamic heating levels and heat loads associated with CES-PAT are lower owing to benign trajectory and short duration.

\section{Exhaust plume heating}

Quick-action solid Escape Motors include HEM and LEM having high burn rate. LEM has a single combustion chamber with four reverse canted nozzles. Four

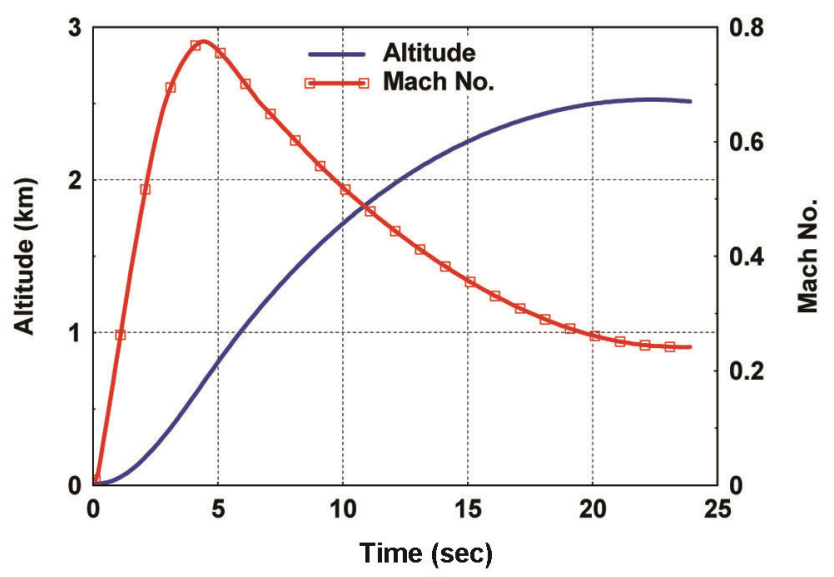

Figure 5. CES-PAT trajectory. 
HEMs are assembled inside each quadrant of CMF. HEM nozzle is truncated to ensure a flushed nozzle exit with vehicle structure to avoid any protrusion. Thus each HEM has a contour nozzle with scarfed exit.

Multiple exhaust jets result in a complex flow field of hot gases laden with hot alumina particles surrounding the LEM case and CMF. These hot exhaust plumes radiate and also impinge on the CES-PAT vehicle surface resulting in severe heating levels.

Computational fluid dynamics (CFD) generated flowfield data are used for estimating convective heat flux on the vehicle surface using engineering methods ${ }^{3}$. Figure 7 shows a typical temperature contour surrounding the vehicle. Heat flux is estimated considering flow over a flat plate. Maximum convective heating levels estimated at shroud and grid fin regions are $2.2 \mathrm{~W} / \mathrm{cm}^{2}$ and $14.2 \mathrm{~W} / \mathrm{cm}^{2}$ respectively.

The exhaust plumes of HEM and LEM are dominant sources of radiative heating. Radiative heat flux on different regions is estimated approximating the exhaust

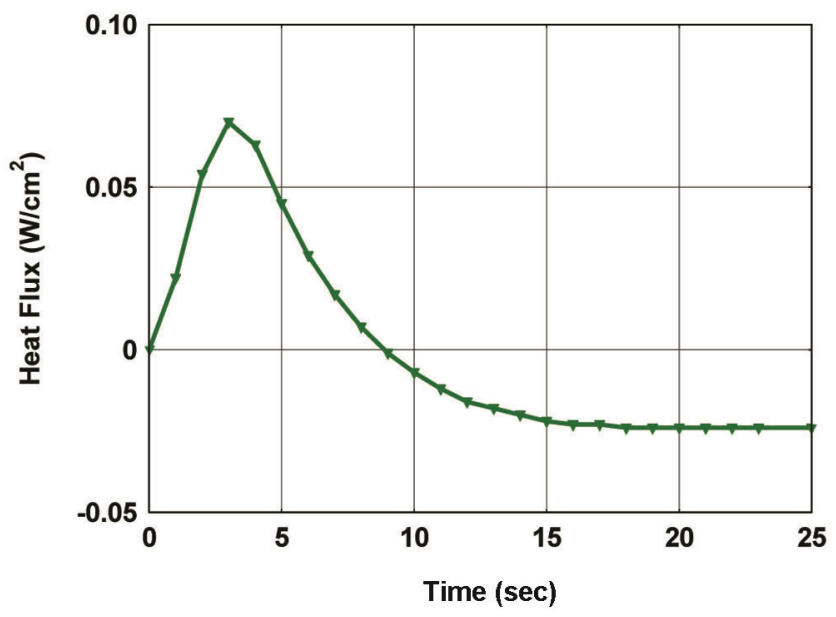

Figure 6. Estimated aerodynamic heating levels.

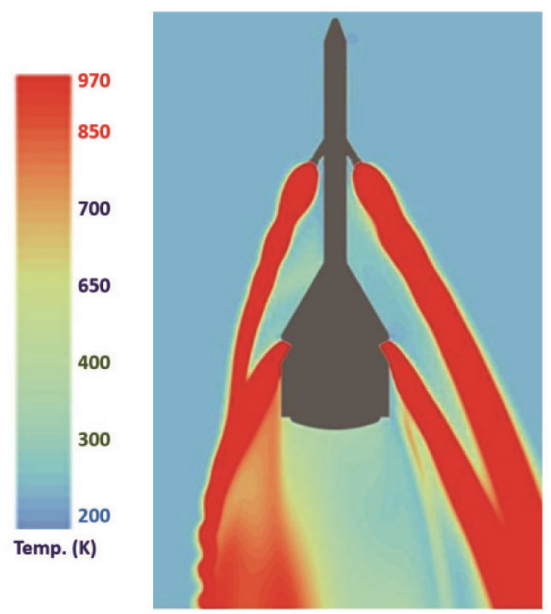

Figure 7. Temperature contour of exhaust jets. plume as a surface radiation model considering view factor $^{4}$. Radiative heat flux is estimated based on motor characteristics, specific impulse, plume temperature at nozzle exit and plume expansion angle. LEM and HEM have a total burn-out time of $8 \mathrm{sec}$ and $5 \mathrm{sec}$ respectively. Heat flux levels are estimated and compared for static test measurement locations. Figure 8 compares the estimated and measured heat flux at motor case locations for steady chamber pressure conditions during LEM static test. There is good agreement between measured and computed heat flux levels. The radiation model is thus verified with heat flux measurements in static tests.

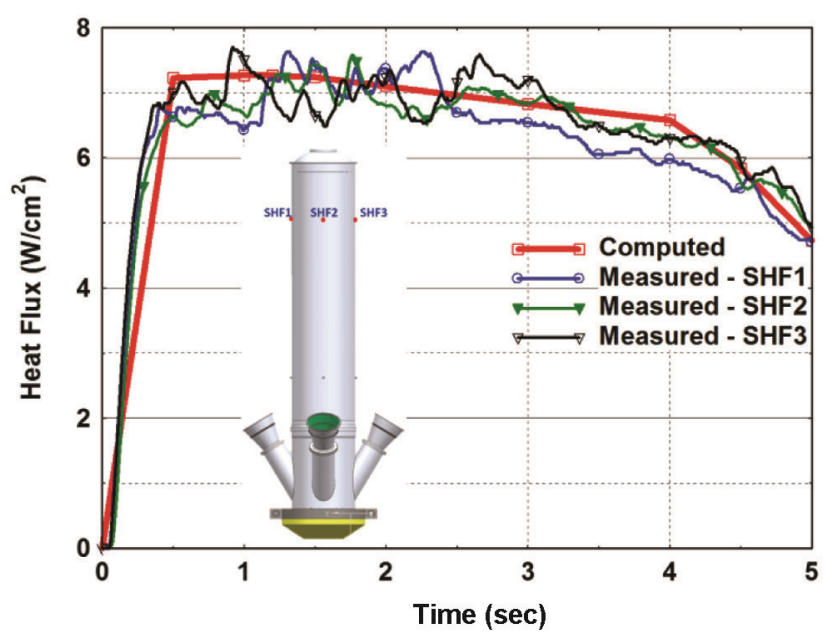

Figure 8. Comparison of estimated and measured heat flux in LEM static test.
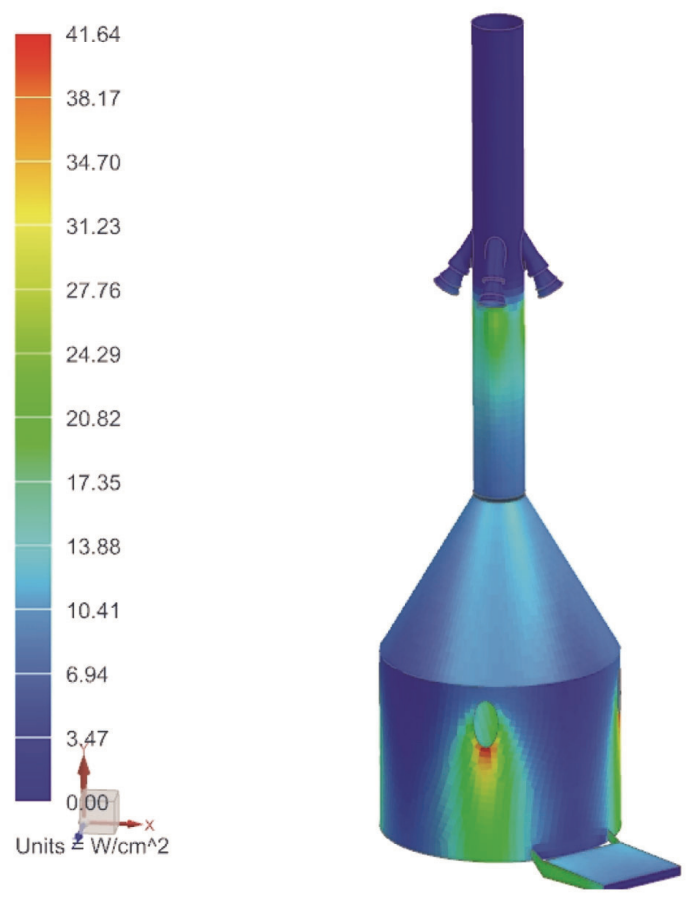

Figure 9. Estimated radiative heat flux distribution.

CURRENT SCIENCE, VOL. 120, NO. 1, 10 JANUARY 2021 
Plume emission characteristics obtained from surface radiation model are imposed as boundary conditions in the three-dimensional finite element model to estimate distribution of radiative heat flux levels on vehicle structure. Figure 9 shows the mapped radiative heat flux levels on vehicle structures. Vehicle surfaces in the close proximity of exhaust plumes are maximum heated zones. CMF cylinder and LEM case experience a maximum radiative heat flux of 42 and $30 \mathrm{~W} / \mathrm{cm}^{2}$ respectively. The transient variation of heat levels is adopted from heat flux measurements in static tests to account for convection and tail-off behaviour for TPS design. Design heat flux levels include margins over estimated values. Figure 10 shows the design heat flux histories at typical locations of the CES-PAT vehicle. CM cylindrical region near HEM nozzle exit has maximum heat flux.

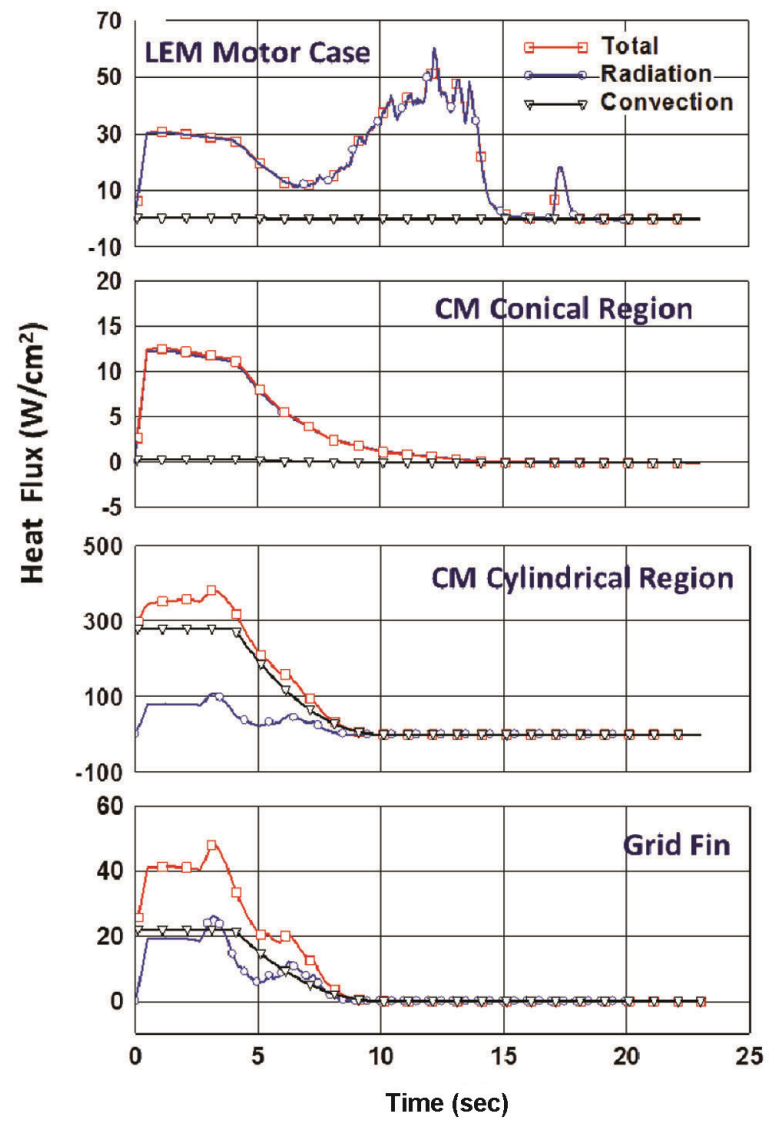

Figure 10. TPS design heat flux histories.

Table 1. Design TPS thickness details

\begin{tabular}{lc}
\hline Location & Design TPS thickness (mm) \\
\hline Fore end region & Nil \\
LEM motor case & 0.4 \\
CM Fairing cone & 0.6 \\
CM Fairing cylinder & 2.0 \\
Grid fin & 0.9 \\
\hline
\end{tabular}

It is seen that aerothermal environments in CES-PAT are dominated by exhaust plume heating which determines the TPS design over vehicle structures.

\section{TPS design}

The external surfaces of CES-PAT vehicle are made of aluminium alloy and steel. To restrict temperature levels within specified limits, thermal paint-based TPS scheme is adopted. TPS design is carried out considering worstcase heating loads and minimum structure thickness of all vehicle regions. One-dimensional thermal response of structures is computed using in-house code ${ }^{5}$. An initial temperature of $40^{\circ} \mathrm{C}$ assuming worst-case SHAR ambient temperature is considered for TPS design. Table 1 summarizes the design TPS thickness at different locations of the CES-PAT vehicle.

\section{Thermal management for avionics}

CM houses electronic packages for telemetry, tracking and command systems, and power systems. These packages are subjected to heat loads due to power dissipation, convection heating from its ambient, and radiation heating from elements, including the structure. In order to ensure their performance till end of flight, temperature levels of these packages have to be maintained within safe operating limits. Thermal environments for the packages for pre-launch and flight phases are estimated to compute the package temperatures. Pre-launch cooling design is carried out for high-power dissipating packages to limit their temperatures within constraints.

Thirty-six avionic packages are mounted on the top and bottom decks inside the CM (Figure 11). The bottom circular deck is made of $62 \mathrm{~mm}$ thick aluminium alloy honeycomb sandwich and top deck sectors are made of aluminium alloy plates.

\section{Theoretical modelling}

During pre-launch operations, coolant air at predetermined mass flow rate and temperature is supplied to $\mathrm{CM}$

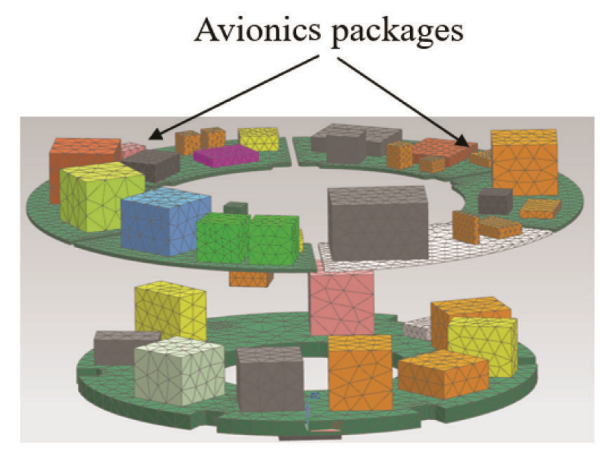

Figure 11. Avionics layout inside CM. 
to control the ambient temperatures. A major portion of the heat dissipated by the packages is convected away by the coolant, thus keeping the temperatures within their constraints till the end of flight. CM structure walls are not exposed to solar radiation during pre-launch phase, as it is inside CMF.

The air temperature inside CM compartment is computed considering convection from structure back wall, coolant flow conditions and power dissipation of avionic packages. Air temperature inside is computed from the following energy balance equation:

$$
\begin{aligned}
& \rho_{\mathrm{f}} \forall_{\mathrm{f}} C_{\mathrm{p}_{\mathrm{f}}} \frac{\mathrm{d} T_{\mathrm{f}}}{\mathrm{d} t} \\
& =\sum_{i=1}^{N} h_{\mathrm{in}, i} A_{\mathrm{s}, i}\left(T_{\mathrm{si}}-T_{\mathrm{f}}\right)+Q_{\mathrm{DISS}}+m C p_{\mathrm{f}}\left(T_{\mathrm{in}}-T_{\mathrm{f}}\right),
\end{aligned}
$$

where $\rho$ is the density, $C_{\mathrm{p}}$ the specific heat, $A$ the area, $h$ the convective heat transfer coefficient, $Q_{\text {DISs }}$ the power dissipation of avionic packages, $m$ the mass flow rate of coolant, $T$ the temperature and $V$ is the volume of the compartment. $f$ is the air inside crew module, si the structure, in the inlet and $i$ is the node number.

The estimated ambient temperature of $\mathrm{CM}$ compartment is $39^{\circ} \mathrm{C}$, which is further used for computing the convective heat transfer from the packages. Finite element model of the package is developed using commercial software NX9.0 (ref. 6). Avionic packages have been modelled as cuboids, and their location, mass, power dissipation and surface finish have been accounted for. Convective heat exchange with the ambient during pre-launch phase and radiation exchange with the structure during flight phase are simulated. Internal heat transfer coefficients are computed using standard correlations for free convection. Package temperatures are to be maintained within $60^{\circ} \mathrm{C}$ from powering $\mathrm{ON}$, which is $5 \mathrm{~h}$ before liftoff till the end of mission. Figure 12 shows the computed temperature contour of avionic packages.

\section{Flight observations and assessment}

\section{Aerothermal}

Aerothermal instrumentation in the CES-PAT flight includes heat flux and temperature measurements on cone region of CMF. These measurements are used to evaluate the design methodology and adequacy of TPS. Owing to hostile thermal environments associated with exhaust plumes, standard thin foil heat flux sensors are not suitable. Hence in-house realized thermopile-type ribbon stack sensors are used for heat flux measurements. Back-wall temperature is measured using resistance temperature detector (RTD) sensor.

Figure 13 shows the location of thermal sensors in cone region of CMF. Three heat flux and three tempera- ture sensors are instrumented along four generators of the cone region in CMF. Figure 14 compares the design and measured heat flux histories during flight. It is seen that the design heat flux levels are higher than flightmeasured values in terms of maximum heat flux and total heat load. These measured heat flux histories are used to predict temperature histories on CMF.

Figure 15 compares computed and measured temperature histories at different locations on the cone region of CMF. There exists good agreement between computed and measured temperature levels, except at lower frustum of the cone region. A sudden rise in back-wall temperature is observed in T3 location, which is not an expected trend for a metallic structure with external insulation. A constant internal heat flux of $49 \mathrm{~W} / \mathrm{cm}^{2}$ for initial $5 \mathrm{sec}$ could only recreate this measured back-wall temperature trend. This internal heating is attributed to suspected hot gas entry through the interface between HEM nozzle exit and CMF cylinder region. Images captured inside CMF during the flight also confirm this phenomenon.

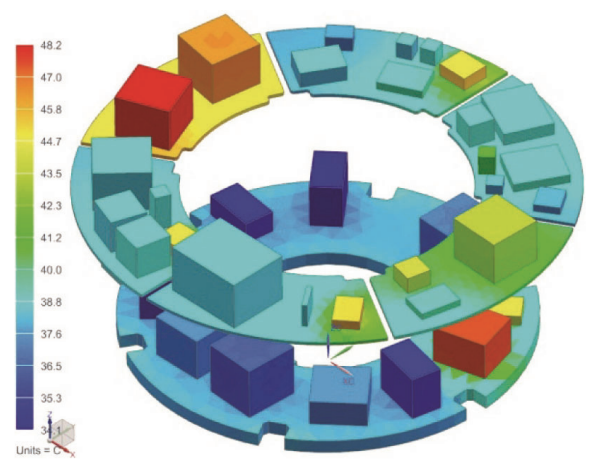

Figure 12. Computed temperature contour of avionics packages at touch down.

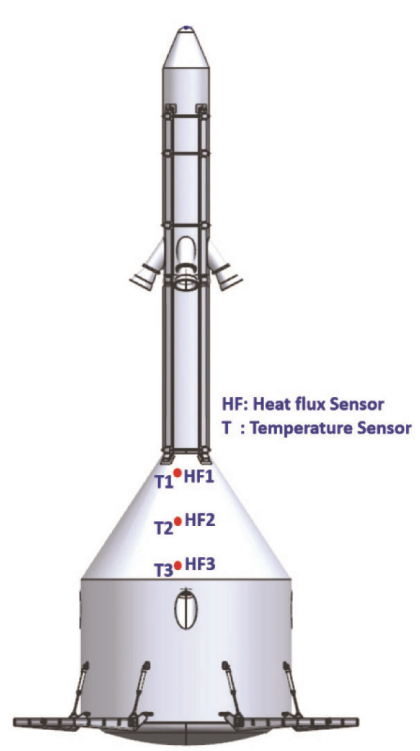

Figure 13. Thermal sensors in CM Fairing.

CURRENT SCIENCE, VOL. 120, NO. 1, 10 JANUARY 2021 


\section{Avionic packages}

Temperature dispersions of avionic packages for prelaunch period are estimated considering the effect of $2 \mathrm{~h}$ launch window and withdrawal of cooling to $\mathrm{CM} 2 \mathrm{~h}$

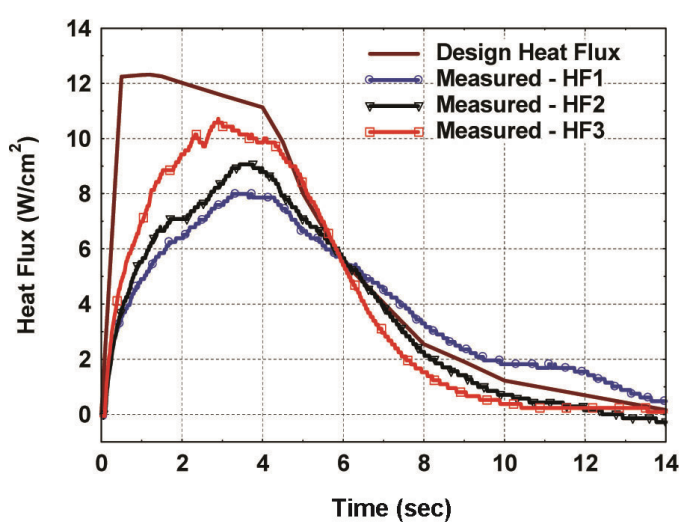

Figure 14. Comparison of design and measured heat flux in the cone region.

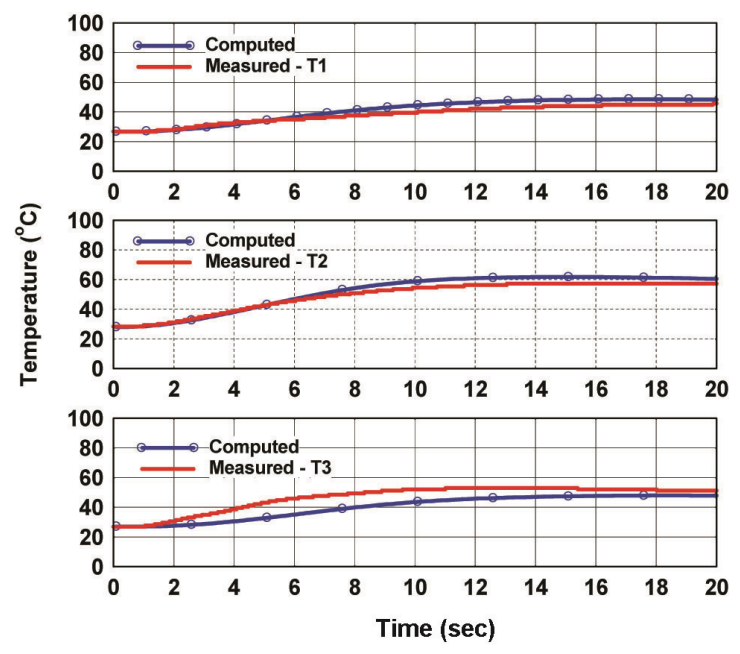

Figure 15. Comparison of computed and measured heat flux in cone region.

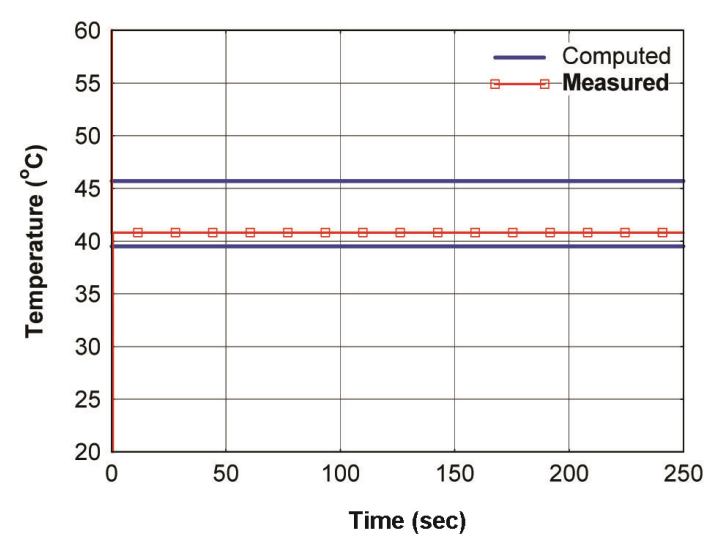

Figure 16. Comparison of computed and measured package temperature inside CM. before lift-off. Figure 16 shows the measured temperature for a typical package inside $\mathrm{CM}$, which is within the computed bounds.

\section{Conclusion}

This article highlights the aerothermal design and TPS design approach followed for the CES-PAT vehicle. Thermal management for avionics packages housed inside CM is also addressed.

- Aerothermal environments are quantified for TPS design.

- Methodology for heat flux estimation is compared with static test measurements and further used for TPS design.

- Aerothermal measurements in the CES-PAT flight show that the design heat flux levels are higher compared to flight-measured levels, thus confirming the adequacy of design approach.

- All the measured temperature levels are well within their allowable constraints. Thermal response analysis for flight conditions provides good comparison between measured and computed temperature histories. This proves the adequacy of design and implemented TPS.

- All avionics packages housed inside CM worked satisfactorily till the end of the CES-PAT mission.

1. Davidson, J. et al., Crew Exploration Vehicle ascent abort overview. In AIAA Guidance, Navigation and Control Conference and Exhibit, AIAA 2007-6590, Hilton Head, South Carolina, USA, 20-23 August 2007.

2. Varghese, R. C., Prabhu, M. R., Anoop, P. and Sundar, B., Aerothermal design, analysis, thermo-structural testing and qualification of RLV-TD. J. Aerosp. Sci. Technol., 2017, 69(3A), 471-479.

3. Van Driest, Turbulent boundary layer in compressible fluids. $J$. Aeronaut. Sci., 1951, 18(3), 145-160.

4. Ram Prabhu, M, Pandey, U., Radhakrishnan, T. V. and Chacko, M. J., Integrated approach for spatial thermal mapping of radiative heat flux in base region of launch vehicles (IHMTC2015-374). In Proceedings of 23rd National Heat and Mass Transfer Conference, First International ISHMT-ASTFE Heat and Mass Transfer Conference, Thiruvananthapuram, 17-20 December 2015.

5. Varghese, R. C., Prabhu, M. R., Anoop, P., Sundar, B., Chacko, M. J. and Raj, P. J., Thermal modeling of umbilical tower during lift off of a launch vehicle. J. Aerosp. Sci. Technol., 2018, 70(2), 77-84.

6. NX-9.0 Thermal Solver TMG Reference Manual, 2013.

ACKNOWLEDGEMENTS. The constant motivation, guidance and support given by Dr V. Ashok (Deputy Director, Aeronautics Entity, VSSC, Thiruvananthapuram) is acknowledged. We also thank Juluri Sreenivasulu (ACD/AERO) for providing the CFD flow field input, and K. Kumar, P. Sunil, B. Anzar and Dileep (ASTS) for support. 